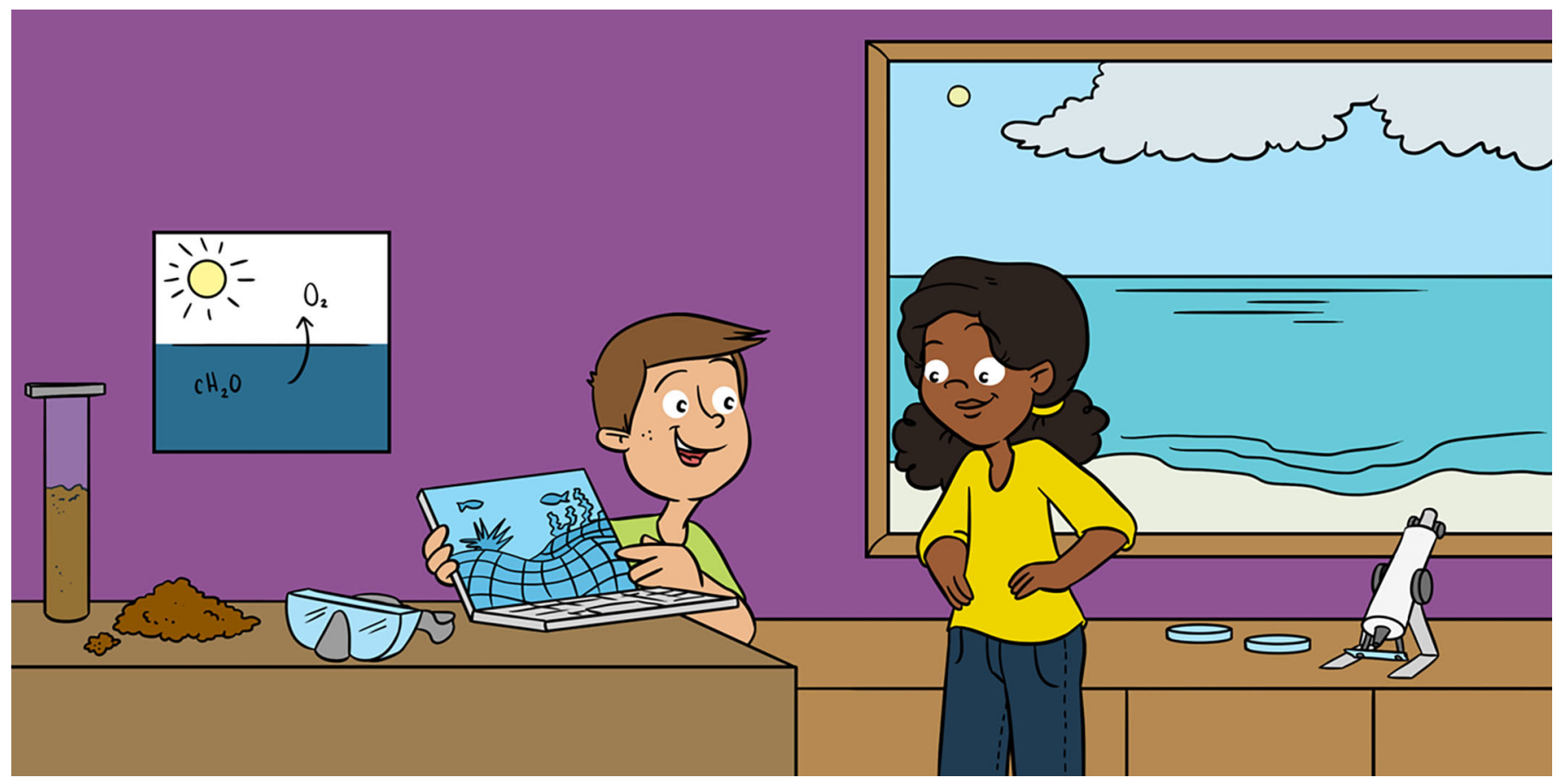

\title{
VIRTUAL REALITY: USING COMPUTER MODELS TO LEARN ABOUT ARCTIC CLIMATE CHANGE
}

\section{James Ward ${ }^{1,2^{*}}$, Felipe S. Freitas ${ }^{1,2}$, Katharine Hendry ${ }^{1}$ and Sandra Arndt ${ }^{3}$ \\ ${ }^{1}$ School of Earth Sciences, University of Bristol, Bristol, United Kingdom \\ ${ }^{2}$ Biogeochemistry and Modelling of the Earth System, Université Libre de Bruxelles, Brussels, Belgium \\ ${ }^{3}$ Department of Earth and Environmental Sciences, Université Libre de Bruxelles, Brussels, Belgium}

YOUNG REVIEWER:

DANNY

AGE: 8
Phytoplankton are the plants of the ocean. When they die and sink, they become a source of delicious food for microorganisms, such as bacteria that live in the mud that settles on the seafloor. As these microorganisms feast on the phytoplankton, nutrients (chemicals needed for growth) stored in the phytoplankton cells are released into the water contained within the mud. These nutrients can then escape into the ocean and be used by new phytoplankton-the circle of life! However, this process is complicated and made up of hundreds of reactions that combine to produce the patterns scientists observe when on expeditions. This is where computers come in handy. We have computer models of the seafloor that can help us to understand the complicated web of reactions that underlie our observations. These models can also be used to simulate extreme conditions, to see how climate change might alter these important processes. 
Figure 1

Photosynthesisers, like phytoplankton, use sunlight to create organic matter, shown here as $\mathrm{CH}_{2} \mathrm{O}$.

Respiration by humans and some

microorganisms uses that organic matter, along with oxygen, to produce energy. Other microorganisms can use different chemicals for respiration. Their respiration reaction is similar, but instead of $\mathrm{O}_{2}$, the equation in the figure would contain nitrate $\left(\mathrm{NO}_{3}^{-}\right)$, sulfate $\left(\mathrm{SO}_{4}^{2-}\right)$, or iron $\left(\mathrm{Fe}(\mathrm{OH})_{3}\right)$.

\section{AUTOTROPH}

An organism that can create its own food from simple substances from its surroundings like $\mathrm{CO}_{2}$, usually by photosynthesis.

\section{ORGANIC MATTER}

Animal or plant based material that becomes food for microorganisms living in the seafloor.

\section{HETEROTROPH}

An organism that cannot create its own food and takes nutrition from existing plant or animal matter.

\section{RESPIRATION}

A chemical reaction that occurs in living things to create the energy they need to survive. As humans, we breathe in oxygen and use it to break down food, which releases the energy stored within it.

\section{DIAGENESIS}

The sum of chemical reactions and physical processes that change sediment when it settles in water.

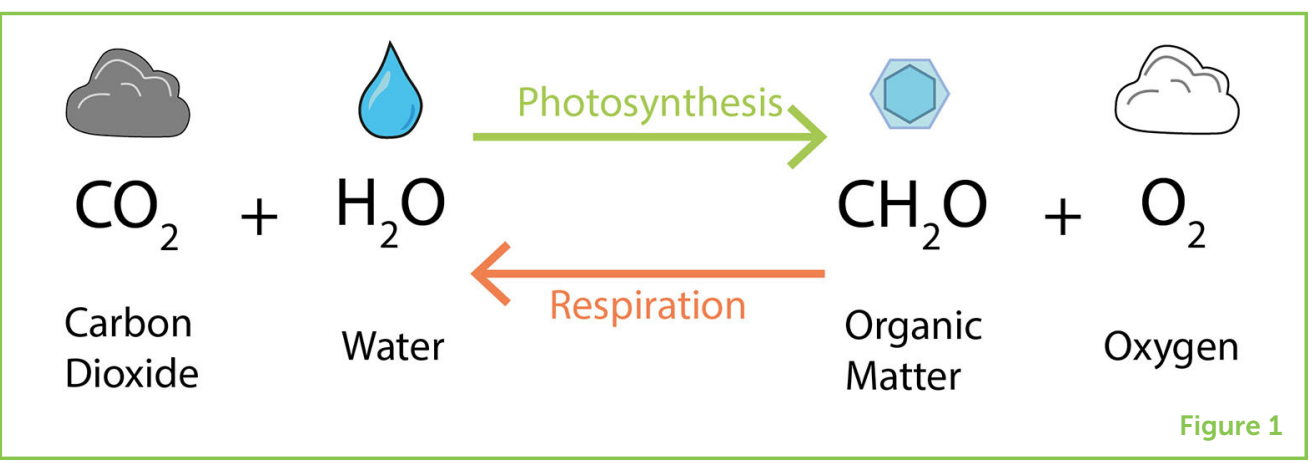

\section{SEAFLOOR MICROORGANISMS}

Phytoplankton are the tiny plants of the ocean. You cannot see individual phytoplankton without a microscope, but they form the base of all ecosystems in the marine world, supporting everything from killer whales to polar bears. These organisms, known as autotrophs, survive by using energy from sunlight, in a process called photosynthesis. This is a process that takes carbon from the atmosphere (in the form of $\mathrm{CO}_{2}$ ) and nutrients from the surface of the ocean and produces food for the phytoplankton to survive (Figure 1). When the phytoplankton die, they sink and can become buried in mud on the seafloor (Figure 2). At this point, they themselves become a great source of delicious food (which we refer to as "organic matter") for tiny microorganisms. The microorganisms that live within this muddy environment are similar to humans, in that they need to eat organic matter to produce the energy needed to survive. This type of organism is known as a heterotroph. As humans, we eat organic matter (fruit, vegetables) and we breathe in oxygen from the air and process everything to produce energy through a reaction called respiration, which is the opposite of photosynthesis (Figure 1). Some microorganisms do this too, if they live close to the ocean bottom water, which is often rich in oxygen; but many microorganisms live deep within the seafloor where there is no oxygen. These microorganisms still eat organic matter, but they have adapted to use other chemicals during respiration, such as nitrate $\left(\mathrm{NO}_{3}^{-}\right)$and sulfate $\left(\mathrm{SO}_{4}^{2-}\right)$. Some can even use solids like iron minerals $\left(\mathrm{Fe}(\mathrm{OH})_{3}\right)$ [1]! The process of organic matter breakdown and the complex web of reactions that happens within the seafloor is known as diagenesis [2].

The diagenesis that occurs on the seafloor is incredibly important because, as the seafloor microorganisms eat, the nutrients stored in their food are released back into the ocean (Figure 2). Sometimes, when the microorganisms are using solid iron minerals for respiration, iron can also be released into the ocean water. Iron is only required in small amounts by phytoplankton, so we refer to it as a micronutrient, but it is vital for their survival and often in short supply! Thanks to diagenesis, instead of all the organic matter that lands on the seafloor 
Figure 2

Large increases in the phytoplankton population are called blooms. The phytoplankton take nutrients [like nitrogen $(\mathrm{N})$, silicon ( $\mathrm{Si})$, iron (Fe), and phosphorous (P)] in from the surface ocean and perform

photosynthesis, then they eventually die and sink (see circle A). At this point, they become organic matter, a source of food for microorganisms in the seafloor. Different types of microorganisms ( $\mathbf{A}$, $\mathbf{B}$, and $\mathbf{C}$ ) eating the food perform respiration.

Microorganism A might use oxygen for respiration, like humans, but $\mathrm{B}$ and $\mathrm{C}$ may use nitrate $\left(\mathrm{NO}_{3}{ }^{-}\right)$ or solid iron minerals $\left(\mathrm{Fe}(\mathrm{OH})_{3}\right)$ (see circle B). As food is broken down during respiration, the nutrients originally taken from the surface by the phytoplankton are released into the mud, and eventually enter the ocean water where they can be reused.

\section{PORE WATER}

Seawater trapped within seafloor mud. We can study this to learn more about the activities of different microorganisms.

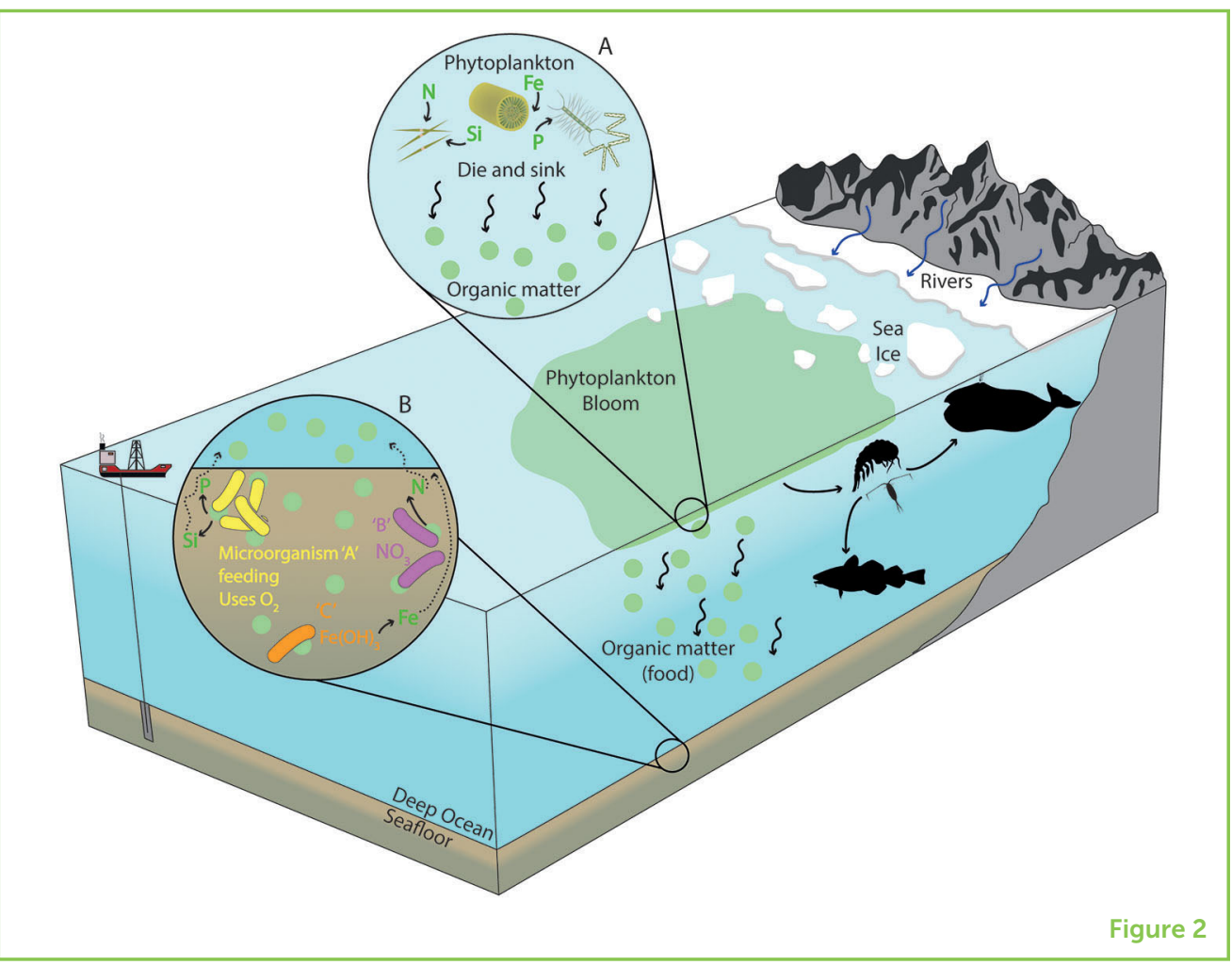

being buried for millions of years, most of the nutrients that land there are returned to the water to be reused by new phytoplankton, to start the cycle all over again. If the seafloor microorganisms did not exist, imagine what would happen to the nutrients the phytoplankton need to take up from the surface ocean. There would be fewer nutrients available because there would be no way of recycling them! This is why we care so much about the process of diagenesis, because phytoplankton that are powered by ocean nutrients are incredibly important for taking $\mathrm{CO}_{2}$ out of the atmosphere, which is necessary to help prevent our carbon emissions from warming the planet even more quickly.

We can study these seafloor processes by going out on ships and collecting tubes of mud, known as cores (Figure 3). We can then take this mud back to our laboratories and measure the concentration of the different chemicals in both the mud itself and in the water trapped within it, called pore water. This information can help us to understand what happens to the organic matter that reaches the seafloor. For example, we can measure how much organic matter there is and how quickly it is being eaten, and we can also look at how the concentrations of the different chemicals used during respiration change from top to bottom in the core. However, there are many processes that can change the concentration of these chemicals, including some that do not involve microorganisms. Therefore, even though we can measure the amounts of certain substances, it is sometimes still very difficult to determine exactly which processes are occurring in the seafloor. If we want to know how climate change 
Figure 3

A sediment core is collected, complete with worms and sponges! A chosen condition, such as the amount of food (organic matter) available for microorganisms, is measured in the laboratory. The amount of food decreases deeper into the core because it is being used up by these microorganisms. By using our model and adjusting it until it matches the data, we can find out which microorganisms are multiplying and feasting at each level and how quickly they are doing so. Each of these microorganisms will do slightly different things. For example, they all eat the same food, but they use different chemicals to break the food down during respiration. Because of this, each microorganism is important for influencing what happens to different chemicals in the seafloor. Computer models allow us to learn even more from the information we collected from the expedition and in the lab.

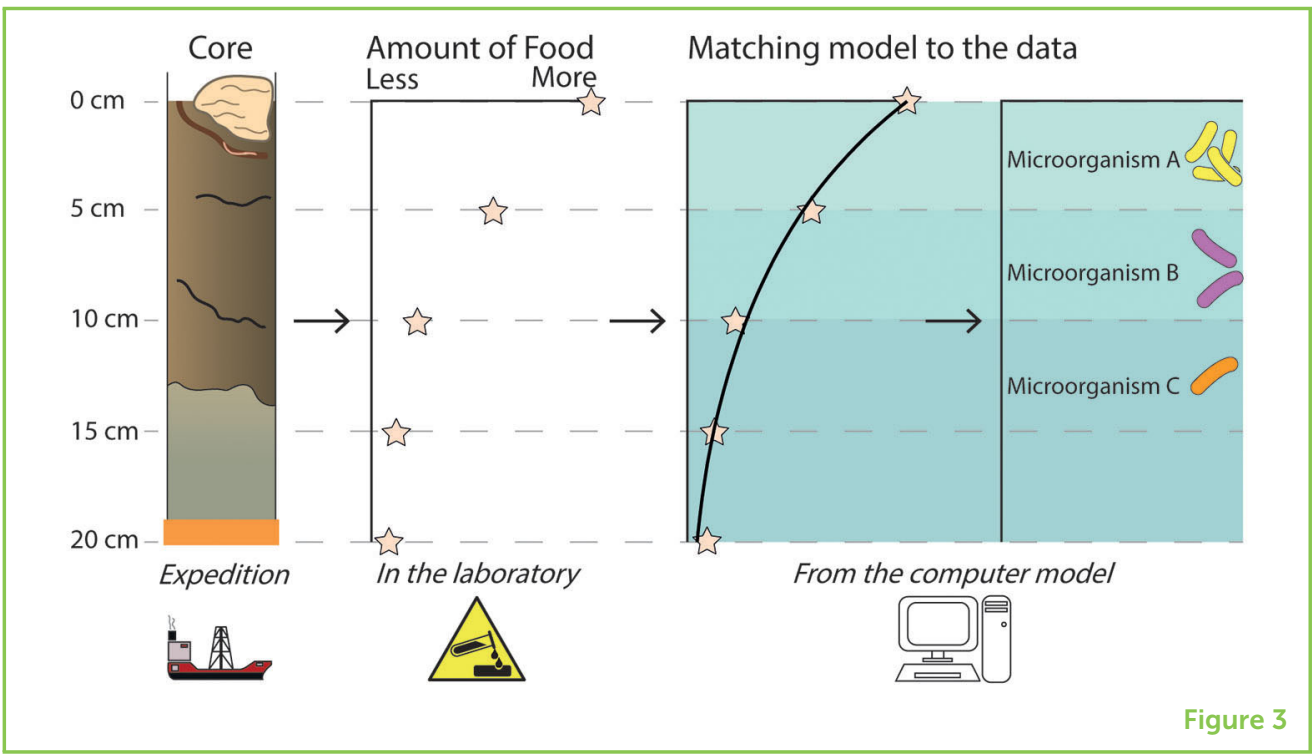

might alter the seafloor, we need to know which processes are actually happening at the places we visit and how important those processes are. This is why computer models are so helpful.

\section{WHAT IS A COMPUTER MODEL?}

A model is just a pretend version of the real world, like a computer game. Models include everything from the flight simulators that help to train pilots, to weather forecasting for TV news. They can exist as simple drawings on a piece of paper, to more complicated forms built with computer code. All models are simplified versions of the real world. They are built on what we know about the world, so they can become more complicated the more we understand about different processes that happen in real life. Unfortunately, more complicated models require more powerful and expensive computers to do the calculations. The set-up of complicated models also requires more observations from the real world, which are not always available. So, when we create computer models, we have to be careful about what we choose to include in the models, because we want to be able to get results quickly but not be too simplistic. For example, really fancy game graphics that show exactly what someone or someplace looks like will need your computer to work much harder than if the people were represented as stick figures and the buildings as plain gray blocks!

In the case of the seafloor, we can use a model called the Biogeochemical Reaction Network Simulator (BRNS) [3, 4]. BRNS has over 40 different chemical reactions and can even simulate things like worms mixing up the mud [5]. However, we only use BRNS for individual cores, not for large areas of the ocean, which means we can look at one location in a lot of detail, but still get our results very quickly with normal computers like you have at home. With BRNS, 


\section{BOUNDARY}

\section{CONDITION}

A value we use to define the type of environment we are looking at. It is like an instruction to help the model to produce a virtual core similar to what we have measured in the lab

\section{MODEL FIT}

When the model produces a virtual core that matches nicely with the data we have produced in the lab. We achieve this by carefully adjusting the boundary conditions. we take the measurements scientists collect during their expeditions and get much more information from them. To do this, we use values known as boundary conditions, which tell the model what type of environment we are looking at. For example, for the Arctic, our boundary conditions include cold temperatures and a shallow seafloor, as well as the amounts of chemical compounds we have measured in the cores and ocean water just above them. These values turn a blank model into a virtual seafloor that represents the Arctic, but the model can be modified to represent anywhere in the world, as long as the information is available. We can change these boundary conditions until the virtual sediment core looks the same as the values we measured in the laboratory from our real core. When the virtual and the real core match, we call this a model fit (Figure 3). The model then lets us see how different reactions in the seafloor add up to generate our observations from the real world. This is useful, as the more we can understand about what is going on in the seafloor now, the more we can learn how it might change over time, if global warming continues to change the conditions of our planet.

\section{ASKING INTERESTING QUESTIONS}

When we have our model fit, we can do whatever we like with our virtual seafloor world without causing any harm to the real environment. We can ask our computer model questions like, "what would happen if all the sea ice in the Arctic melted?" This means we can look at what would happen to the seafloor if the world were different, which is an important step toward understanding what our oceans might look like in the future. Governments need this information when making decisions that might affect climate change. In the Arctic, the melting of sea ice is increasing the area where phytoplankton can grow, so our seafloor microorganisms might have more organic matter delivered to them in the future. We can use our model to test this and see how it might impact the seafloor microorganism communities and what the influence could be on the whole Arctic ecosystem.

\section{CONCLUSIONS}

Our world is changing very quickly due to climate change and scientists can use models like BRNS to understand what our planet might look like in the future. Going to the places that are changing most rapidly, like the Arctic, can be very helpful, but it is also very expensive and there is only so much we can measure because of time! Frustratingly, there are some processes we cannot measure directly, even though we might know they are happening. We also cannot time travel and go on expeditions in the future or melt sea ice to see how this would impact the seafloor. This is why modeling is such a powerful tool. However, it is very important to remember that successful modeling relies on large groups of scientists from 
different backgrounds working together and sharing information from countless hours of expedition and laboratory work, to make sure the model best represents the real world!

\section{ACKNOWLEDGEMENTS}

The Changing Arctic Ocean Seafloor (ChAOS) project (NE/P005942/1) is part of the Changing Arctic Ocean programme, funded by UKRI Natural Environment Research Council (NERC).

\section{REFERENCES}

1. Kristensen, E. 2000. Organic matter diagenesis at the oxic/anoxic interface in coastal marine sediments, with emphasis on the role of burrowing animals. Hydrobiologia 426:1-24. doi: 10.1023/A:1003980226194

2. Boudreau, B. 1997. Diagenetic Models and Their Implementation. Berlin; Heidelberg: Springer Berlin Heidelberg.

3. Regnier, P., Jourabchi, P., and Slomp, C. 2003. Reactive-Transport modeling as a technique for understanding coupled biogeochemical processes in surface and subsurface environments. Netherlands J Geosci. 82:5-18. doi: 10.1017/S00167 74600022757

4. Aguilera, D., Jourabchi, P., Spiteri, C., and Regnier, P. 2005. A knowledge-based reactive transport approach for the simulation of biogeochemical dynamics in Earth systems. Geochem. Geophys. Geosyst. 6:Q07012. doi: 10.1029/2004GC 000899

5. Meysman, F., Middelburg, J., and Heip, C. 2006. Bioturbation: a fresh look at Darwin's last idea. Trends Ecol. Evol. 21:688-95. doi: 10.1016/j.tree.2006.08.002

SUBMITTED: 04 November 2019; ACCEPTED: 07 August 2020;

PUBLISHED ONLINE: 28 September 2020.

EDITED BY: Kirsty C. Crocket, University of Edinburgh, United Kingdom

CITATION: Ward J, Freitas FS, Hendry K and Arndt S (2020) Virtual Reality: Using Computer Models to Learn About Arctic Climate Change. Front. Young Minds 8:125. doi: 10.3389/frym.2020.00125

CONFLICT OF INTEREST: The authors declare that the research was conducted in the absence of any commercial or financial relationships that could be construed as a potential conflict of interest.

COPYRIGHT (c) 2020 Ward, Freitas, Hendry and Arndt. This is an open-access article distributed under the terms of the Creative Commons Attribution License (CC BY). The use, distribution or reproduction in other forums is permitted, provided the original author(s) and the copyright owner(s) are credited and that the original publication in this journal is cited, in accordance with accepted academic practice. No use, distribution or reproduction is permitted which does not comply with these terms. 

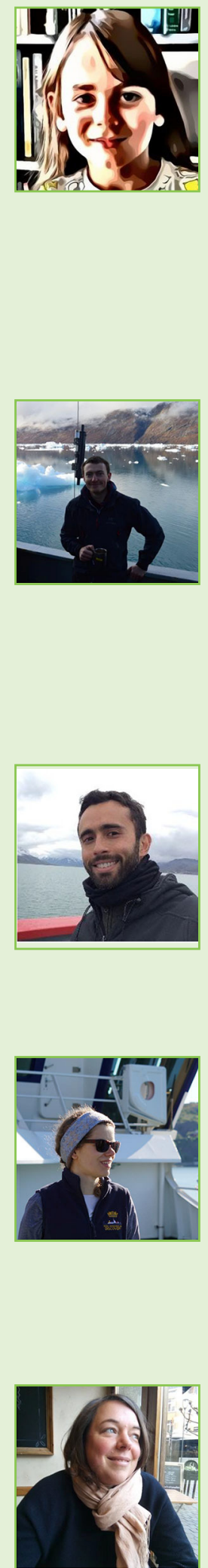

\section{YOUNG REVIEWER}

\section{DANNY, AGE: 8}

Danny loves science and engineering. He is very interested in space and computers. His dream is to be a Pokemon scientist, or failing that, an architect, or an engineer designing games consoles. Danny is happiest when he is inventing new ideas and crafting prototypes. He has set his heart on creating the first real life Pokemon, and has already prototyped a cardboard DNA machine to write Pokemon DNA. We hope soon to introduce him to the concept of scientific ethics...

\section{AUTHORS}

\section{JAMES WARD}

I have always been fascinated by the earth, especially the polar regions. I received my undergraduate degree in Geology from the University of Bristol and decided that studying for a Ph.D. would be an amazing opportunity to turn my interest into something useful for science and the environment! I currently work on seafloor sediments from the Barents Sea, looking at how climate change and sea-ice retreat might impact nutrient cycling. You will either find me in the lab measuring silicon isotopes in pore waters or at my desk trying to model them! *jamespj.ward@abristol.ac.uk

\section{FELIPE S. FREITAS}

I am a post-doctoral researcher at the School of Earth Sciences, University of Bristol, investigating how organic matter deposited onto seafloor is transformed and buried. I use computer modeling in combination with field and laboratory observations to understand what controls organic matter preservation and degradation in marine sediments, as well as the implications of those processes for carbon cycling and Earth's climate.

\section{KATHARINE HENDRY}

I am a biogeochemist and oceanographer from the University of Bristol. I started my career in the waters around Antarctica but have moved toward the north and now also work in the subarctic and Arctic. My interests lie in understanding how the essential nutrients that fuel life get into-and move around within-the oceans. I use a combination of novel sampling methods, sensors, and cutting-edge laboratory techniques to understand the key processes that control the chemistry of our polar seas.

\section{SANDRA ARNDT}

I am a biogeochemical modeler from Université Libre de Bruxelles in Belgium. My research focuses on the development and application of models that are designed to advance our understanding of how essential nutrients for life move around within the oceans and to shed light on the role of the environment in past, present, and future carbon cycling and climate. I am especially interested in the burial of carbon in marine sediments over time and in different environments, and its impact on global nutrient cycles and climate. 